\title{
Fatores relacionados aos casamentos de longa duração: panorama a partir de uma revisão integrativa
}

\author{
Suzel Alves Goulart ${ }^{1}$ \\ Ana Carolina Graner Araújo Oliveira ${ }^{1}$ \\ Fabio Scorsolini-Comin ${ }^{2}$ \\ Manoel Antônio dos Santos ${ }^{2}$ \\ ${ }^{1}$ Universidade Federal do Triângulo Mineiro. Cidade, MG, Brasil. \\ ${ }^{2}$ Universidade de São Paulo. Ribeirão Preto, SP, Brasil.
}

\begin{abstract}
Resumo
Este estudo teve por objetivo apresentar uma revisão integrativa da literatura acerca dos casamentos de longa duração. A revisão foi operacionalizada mediante consulta às bases/bibliotecas LILACS, PePSIC, SciELO e PsycINFO, de janeiro de 2009 a junho de 2017, amparada na estratégia PICO. A pergunta norteadora foi: Como os casamentos de longa duração são abordados na literatura científica nacional e internacional? Foram recuperados 22 artigos empíricos, nove deles brasileiros. Os casamentos longevos promovem apreciação na qualidade de vida, conferida pelo elevado nível de satisfação conjugal, repercutindo na saúde física e emocional dos cônjuges. As relações sexuais e o amor são considerados dimensões essenciais para a manutenção do matrimônio e a sua ausência é motivo de conflito conjugal. Os antagonismos tendem a abrandar com o tempo, sendo importante criar estratégias saudáveis de enfrentamento. Além disso, em casais idosos percebe-se uma necessidade acentuada de apoio social, que pode ser proporcionado pelo parceiro ou pela família.
\end{abstract}

Palavras-chave: casamento, relações conjugais, revisão de literatura.

\section{Factors related to long-term marriage: overview from an integrating review}

\begin{abstract}
This study aimed to present an integrative review of the literature on long term marriages. The review was operationalized through consultation with LILACS, PePSIC, SciELO and PsycINFO databases, from January 2009 to June 2017, supported by the PICO strategy. The guiding question was: How are long-term marriages addressed in national and international scientific literature? 22 empirical articles were recovered, nine of them Brazilian. Long-term marriages promote appreciation in the quality of life, conferred by the high level of marital satisfaction, affecting the physical and emotional health of the spouses. Sexual relations and love are considered essential dimensions for the maintenance of marriage and their absence is cause for marital conflict. Antagonisms tend to slow down over time, and it is important to create healthy coping strategies. In addition, in elderly couples there is a marked need for social support, which can be provided by the partner or the family.
\end{abstract}

Keywords: marriage, marital relationships, literature review.

\section{Factores relacionados a las bodas de larga duración: panorama a partir de una revisión integrativa}

\section{Resumen}

Este estudio tuvo por objetivo presentar una revisión integrativa de la literatura acerca de los matrimonios de larga duración. La revisión fue elaborada mediante consulta a las bases LILACS, PePSIC, SciELO y PsycINFO, de enero de 2009 a junio de 2017, amparada en la estrategia PICO. La pregunta orientadora fue: ¿Cómo los matrimonios de larga duración se abordan en la literatura científica nacional e internacional? Se recuperaron 22 artículos empíricos, nueve de ellos brasileños. Las bodas longevas promueven la apreciación en la calidad de vida, conferida por el elevado nivel de satisfacción conyugal, repercutiendo en la salud física y emocional de los cónyuges. Las relaciones sexuales y el amor son consideradas dimensiones esenciales para el mantenimiento del matrimonio y su ausencia es motivo de conflito conyugal. Los antagonismos tienden a ralentizarse con el tiempo, siendo importante crear estrategias sanas de enfrentamiento. Además, en parejas ancianas se percibe una necesidad acentuada de apoyo social, que puede ser proporcionado por el cónyuge o por la familia.

Palabras clave: matrimonio, relaciones conyugales, revisión de literatura. 
A literatura científica revela que as relações conjugais têm sido foco de investigações de pesquisadores brasileiros e estrangeiros, uma vez que os relacionamentos íntimos são considerados dimensões centrais na vida adulta, sendo a conjugalidade uma das vivências mais complexas do ciclo vital. Estudos mostram que a qualidade da relação afetiva pode ter implicações na saúde mental, física e na vida social e profissional, sendo preditora de longevidade, condições gerais de saúde e processos de adoecimento (AlvesSilva, Scorsolini-Comin, \& Santos, 2016; FéresCarneiro \& Diniz-Neto, 2010).

Historicamente, o surgimento do casamento como instituição esteve ligado à regulamentação das atividades biológicas, como a reprodução e o exercício da sexualidade. Assim, por muito tempo o casamento teve como função precípua legitimar a perpetuação da espécie (Zordan, Falcke, \& Wagner, 2009). Diversos autores ressaltam que, na sociedade atual, o tradicional e o contemporâneo coexistem nos relacionamentos conjugais (Amorim \& Stengel, 2014; Vieira \& Stengel, 2010). Essas mudanças estão sendo engendradas para responder às exigências de uma sociedade em transição, cujos valores hegemônicos e regras econômicas, culturais e sociais, interesses de classe e construções de gênero estão em constante mutação (Féres-Carneiro \& Diniz Neto, 2010). Diante desse panorama de transformações aceleradas, Zordan et al. (2009) apontam que o casamento tem sido alvo de intensos questionamentos, devido às alterações promovidas em algumas de suas características primárias. Nesse sentido, o aspecto de formação da conjugalidade pode ser visto como dinâmico e contínuo, e não meramente como uma transição que envolve as fases inicias de engajamento amoroso, pois são os padrões de relacionamento que mantêm a conjugalidade e sua qualidade no decorrer do tempo, permitindo que esta resista às diversas circunstâncias, sobrevivendo às mudanças previsíveis e imprevisíveis do ciclo de vida nas sociedades hipermodernas (FéresCarneiro, 2003; Féres-Carneiro \& Diniz Neto, 2010).

Diante do exposto, ressalta-se que o conjunto de transformações culturais, sociais e conceituais acerca da conjugalidade implica mudanças nos motivos, motivações e expectativas em relação ao casamento. O estudo de Zordan et al. (2009), que teve como objetivo identificar motivos e expectativas de adultos jovens frente ao casamento, sistematizou, entre os motivos pessoais apresentados como justificativa para o casamento, aqueles vinculados à relação amorosa e à afinidade dos parceiros. Já em relação aos motivos familiares, os adultos jovens indicaram a expectativa e importância que os pais atribuíam ao casamento, principalmente suas mães. Observou-se que motivos socioeconômicos têm maior concordância com o fato de oficializar uma união perante à sociedade. Entre os motivos religiosos, aparecem como mais significativos a valorização do casamento pelas diferentes religiões e a hipótese de que quem tem fé considera o casamento como um ato sagrado. Quanto às expectativas com relação ao casamento, os participantes da pesquisa manifestaram, especialmente, o companheirismo, o amor e a segurança emocional, isto é, valores que se referem especificamente à relação afetivo-emocional do casal. Ressaltaram também que, a escolha pelo casamento na contemporaneidade é motivada, principalmente, por fatores subjetivos, predominando as expectativas referentes à qualidade da relação conjugal.

Por outro lado, quando os cônjuges não aceitam que a relação conjugal não corresponde às suas expectativas, ou quando os padrões de manutenção do vínculo são modificados, ao ponto de a união não poder mais ser definida pelos cônjuges, ou ao menos por um deles, como um espaço comum de relação e desenvolvimento conjugal, pode ocorrer a dissolução dos laços conjugais, resultando na separação. Essas dimensões também são abordadas nos estudos disponíveis sobre a conjugalidade, uma vez que, no processo de separação, a identidade conjugal, construída no casamento, vai aos poucos se desfazendo, o que leva os cônjuges a uma redefinição de suas identidades individuais (FéresCarneiro \& Diniz Neto, 2010; Rolim \& Wendling, 2013).

Diante do exposto, percebe-se que as motivações para o casamento se apoiam, sobretudo, na legitimação dos sentimentos, em que os noivos compartilham idealizações em torno do casamento e da união conjugal, as quais suscitam expectativas que, se não forem atendidas, prenunciam um mal-estar no relacionamento, tornando o divórcio uma possibilidade no horizonte do casal, o que sempre envolve fatores multidimensionais (Quissini \& Coelho, 2014). Contudo, não é porque muitos casamentos tenham fim que não seja possível que um casal consiga manter uma relação conjugal duradoura (Alves-Silva, ScorsoliniComin, \& Santos, 2016).

Segundo o Instituto Brasileiro de Geografia e Estatística (IBGE, 2013), casamentos com mais de 15 anos de duração estão acima da média nacional. Contudo, o estudo de Alves-Silva et al. (2016) aponta que a literatura a respeito dos casamentos de longa duração ainda apresenta discordâncias sobre quantos anos uma relação conjugal deve durar para que seja considerada como tal. Ressaltam que, para a maioria dos estudiosos do tema, o relacionamento duradouro 
é aquele que se mantém por período considerável de tempo sem, no entanto, determinar uma duração fixa que possa servir de referência ou padrão absoluto.

Em relação à longevidade dos relacionamentos conjugais, Norgren, Souza, Kaslon, Hammerschmide e Sharlim (2004) apontam os principais motivos para se manter essa condição, dentre eles: o fato de os cônjuges acreditarem que o casamento é uma parceria para a vida toda, a sensação de responsabilidade que um cônjuge tem pelo cuidado do outro e o fato de haver amor cimentando a relação, a própria qualidade percebida do vínculo afetivo estabelecido e as experiências de tomada de decisões em conjunto. A crença religiosa foi outro fator evidenciado como influenciador da continuidade dos relacionamentos conjugais.

Para Bachand e Caron (2001), o amor, origens e interesses semelhantes, e o sentimento de amizade são benefícios auferidos dos casamentos de longa duração e também as causas de sua longevidade. Além desses aspectos, os casais longevos parecem estar envolvidos com as questões atuais do casamento, buscando alternativas para evitar a rotina e continuar investindo no relacionamento. Os casais que se consideram satisfeitos com o casamento demonstram que, como instituição, ele permanece em constante evolução, pois os cônjuges continuam a investir e acreditam que é possível manterem-se casados por muito tempo e continuarem juntos para que possam enfrentar quaisquer circunstâncias da vida (Alves-Silva et al., 2016; Norgren et al., 2004).

Ressalta-se que as pesquisas nacionais sobre os casamentos de longa duração estão em ascensão. De acordo com a revisão de Alves-Silva et al. (2016), publicações recentes têm oportunizado a investigação mais direta desse fenômeno, o que coloca os casais longevos como um público potencial para novos estudos. Nesse sentido, os relacionamentos de longa duração podem se constituir como um locus para a investigação das transformações da conjugalidade ao longo do tempo, oportunizando o acesso às motivações, fontes de conflitos e também estratégias de resolução empregadas pelos casais. Apesar do vasto interesse científico no casamento, é premente a necessidade de ampliação do repertório acerca dos fatores implicados na conjugalidade ao longo do tempo, abarcando possíveis mudanças, permanências e rupturas. Será que esses movimentos têm sido suficientemente abordados e investigados pela literatura? Diante dos argumentos apresentados, considera-se necessário conhecer, mapear e sintetizar o panorama atual da produção científica que aborda o casamento de longa duração e indicar alternativas de investigação futura no campo da conjugalidade. A partir do exposto, este estudo teve por objetivo apresentar uma revisão integrativa da literatura científica acerca dos casamentos de longa duração.

\section{Método}

\section{Tipo de estudo e pergunta norteadora}

Trata-se de uma revisão integrativa da literatura científica, considerada um dos métodos de pesquisa utilizados na prática baseada em evidências (PBE) (Mendes, Silveira, \& Galvão, 2008; Valdanha, Scorsolini-Comin, Peres, \& Santos, 2013). De modo congruente com os pressupostos do método, a estratégia PICO foi empregada para a construção da pergunta de pesquisa (Santos, Pimenta, \& Nobre, 2007). Desse modo, foi definida a seguinte pergunta norteadora: Como os casamentos de longa duração $(\mathrm{P})$ são abordados (I) na literatura científica $(\mathrm{O})$ ?

\section{Bases consultadas}

Para a realização da revisão de literatura foram consultadas as bases indexadoras/bibliotecas SciELO, PePSIC, LILACS e PsycINFO. Os descritores utilizados foram "casamentos de longa duração", "conjugalidade", "relação conjugal" e "casamento and idoso", bem como os seus termos equivalentes em inglês, respectivamente, "long term marriage", "conjugality", "marital relationship" e "marriage and elderly", de acordo com a DeCS (Descritores em Ciências da Saúde) e com a Terminologia PsiAlfabética acessada via BVS-Psi. O operador booleano "AND" foi utilizando em todas as bases de dados.

\section{Critérios de inclusão}

Os critérios estabelecidos para a inclusão foram: (a) artigos científicos indexados nas bases selecionadas; (b) redigidos nos idiomas português e inglês; (c) publicados entre janeiro de 2009 e junho de 2017; (d) sem restrição de abordagem teórica ou delineamento metodológico; e (e) com temática pertinente ao objetivo da revisão e que contribuíssem para responder à questão norteadora.

\section{Critérios de exclusão}

(a) Livros, capítulos, dissertações, teses, resumos, cartas, resenhas, notícias e revisões de literatura; (b) artigos anteriores a 2009 ou posteriores a junho de 2017; (c) temática distante da proposta pela revisão ou que não contribuísse para responder à questão norteadora. Esses critérios foram estabelecidos pela necessidade de selecionar materiais que garantissem a qualidade do estudo. Já a escolha por artigos entre os anos de 2009 e 2017, visou abarcar publicações mais recentes 
e apresentar um panorama sobre os estudos atuais no cenário científico em relação ao tema proposto.

\section{Procedimento}

O levantamento bibliográfico foi realizado por dois juízes independentes, familiarizados com os procedimentos de revisão, em um primeiro momento (julho de 2016), processo este repetido em junho de 2017 para verificar novos estudos possivelmente publicados após o primeiro levantamento. Os descritores em português e inglês foram empregados nas bases/bibliotecas selecionadas. Em um primeiro momento, foi feita uma leitura dos resumos encontrados $(n=2951)$ a partir dos termos utilizados, excluindo aqueles que não se enquadravam nos critérios de inclusão propostos, ou seja, publicações não veiculadas no formato de artigos científicos ou que não tinham o texto completo disponibilizado nas bases consultadas, que eram redigidas em outro idioma que não o português e inglês e que estavam fora do recorte temporal estipulado $(n=2888)$. Após uma primeira seleção, feita a partir da leitura minuciosa dos resumos, 63 artigos foram selecionados e lidos na íntegra. Desses, 41 foram excluídos por se tratarem de estudos realizados com pessoas casadas, mas que não abordavam necessariamente o casamento de longa duração, ou por não contribuírem significativamente para responder à questão norteadora delimitada. Assim, os 22 artigos que restaram devido à maior proximidade com o tema de interesse, constituíram o corpus de análise do presente estudo. O procedimento de seleção, análise e composição da amostra está representado graficamente na Figura 1.

As discordâncias entre os dois juízes foram apreciadas por um terceiro juiz, que decidiu sobre a inclusão ou não do material. Os artigos recuperados foram categorizados para posterior discussão, organizada a partir de cinco núcleos temáticos que retratavam os conteúdos dos artigos selecionados para compor o corpus da revisão. Os núcleos delimitados foram: (i) Satisfação conjugal e benefícios para a saúde; (ii) Amor e sexualidade em casamentos de longa duração; (iii) Conflito conjugal: motivos e estratégias de enfrentamento; (iv) e Suporte social, família e habilidades dos cônjuges. Esses núcleos foram construídos tomando por base as temáticas exploradas em cada estudo e os seus principais achados, tendo a questão norteadora da revisão como referência, ou seja, a partir das proximidades identificadas entre os estudos recuperados. Os núcleos temáticos, mais do que um retrato dos conteúdos explorados na literatura, revelam um processo didático de organização do conhecimento, com vistas a possibilitar responder à questão norteadora.

\section{Resultados}

Dos estudos selecionados, nove são nacionais (e.g. Alves-Silva, Scorsolini-Comin, \& Santos, 2017; Costa \& Mosmann, 2015a, 2015b; Costa, Falcke, \& Mosmann, 2015c), 11 foram publicados nos Estados Unidos (e.g. Berg, Schindler, Smith, Skinner, \& Beveridge, 2011; Donoho, Seeman, Sloan, \& Crimmins, 2015; Petrican, Bielak, Schimmak, \& Moscovitch, 2010) um na Alemanha (Landis, PeterWight, Martin, \& Bodenmann, 2013) e outro na Suíça (Perrig-Chiello, Hutchison, \& Morselli, 2015). Esses resultados evidenciam que, mesmo contendo no corpus um relevante número de pesquisas nacionais, estas são centralizadas em poucos grupos de pesquisa, notando-se a repetição de autores e instituições. Tal aspecto corrobora a conclusão do estudo de revisão de Alves-Silva et al. (2016), que focalizou especificamente o contexto brasileiro, haja vista a produção de estudos nacionais sobre esse fenômeno nos últimos anos, o que pode denotar o crescente

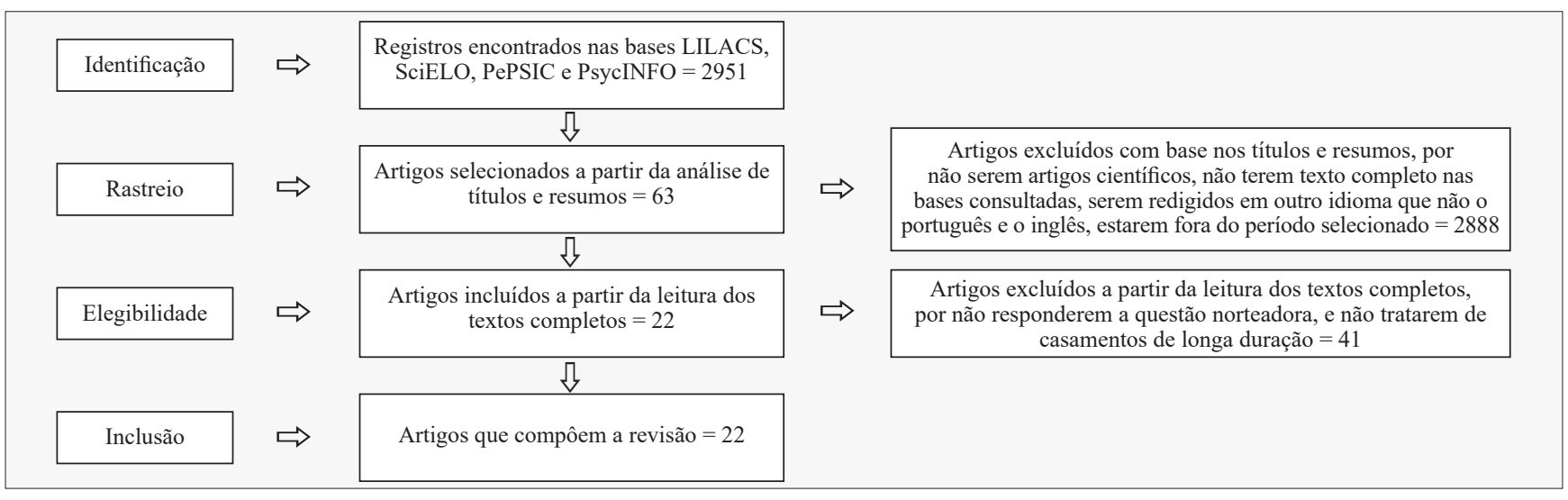

Figura 1. Fluxograma dos procedimentos de seleção dos artigos, de acordo com as diretrizes PRISMA para revisões sistemáticas. 
interesse por parte dos pesquisadores em investigar o fenômeno da conjugalidade nesse público específico. Percebe-se também que, na maioria dos estudos selecionados, foram utilizados métodos quantitativos (e.g. Danohoet al., 2015; Sabey, Rauer, \& Jensen,
2014; Sandberg, Marley, \& Harper, 2009), os quais são amplamente discutidos no âmbito das ciências sociais. Os instrumentos e amostras empregados encontram-se sumarizados na Tabela 1.

TABELA 1

Instrumentos e métodos empregados nos estudos sobre casamentos de longa duração $(\mathrm{n}=22)$

\begin{tabular}{|c|c|c|c|}
\hline Referência & Tempo de duração dos relacionamentos & Método & Amostra \\
\hline Sandberg et al. (2009) & Média de 36 anos de duração. & Quanti & $\begin{array}{l}536 \text { casais, com média de idade dos maridos de } \\
64,98 \text { anos e das esposas de } 62,56 \text { anos. }\end{array}$ \\
\hline Sardinha et al. (2009) & $\begin{array}{l}\text { Duração variou de sete a } 38 \text { anos; média de } \\
22 \text { anos de duração. }\end{array}$ & Quanti & $\begin{array}{l}50 \text { casais casados havia pelo menos sete anos e } \\
\text { com no mínimo ensino médio completo. }\end{array}$ \\
\hline Gerstorf et al. (2009) & Média de 45,9 anos de duração. & Misto & 304 casais acima dos 70 anos. \\
\hline Mazzoleni et al. (2009) & Média de 15 anos de duração. & Quanti & $\begin{array}{l}25 \text { esposas de jogadores patológicos e } \\
25 \text { esposas de não jogadores. }\end{array}$ \\
\hline Petrican et al. (2010) & $\begin{array}{l}\text { Duração variou de } 18 \text { a } 56 \text { anos; média de } \\
42,7 \text { anos de duração. }\end{array}$ & Misto & 40 casais de idosos. \\
\hline Berg et al. (2011) & $\begin{array}{l}\text { Casais de meia-idade: duração variou de cinco } \\
\text { a } 53 \text { anos; média de } 18,5 \text { anos de duração. } \\
\text { Casais idosos: duração variou de cinco a } \\
31 \text { anos; média de } 36,4 \text { anos de duração. }\end{array}$ & Quanti & $\begin{array}{l}146 \text { casais de meia-idade e } 154 \text { casais de } \\
\text { idosos. }\end{array}$ \\
\hline Elliott et al. (2008) & $\begin{array}{l}\text { Duração variou de oito a } 52 \text { anos; média de } \\
25 \text { anos de duração. }\end{array}$ & Quali & 31 casais. \\
\hline Rosowsky et al. (2012) & $\begin{array}{l}\text { Duração variou de } 40 \text { a } 65 \text { anos; média de } \\
49,2 \text { anos de duração. }\end{array}$ & Quanti & $\begin{array}{l}32 \text { casais em casamentos de longa duração, } \\
\text { com média de idade dos maridos de } 74,2 \text { anos } \\
\text { e das mulheres de } 72,5 \text { anos. }\end{array}$ \\
\hline O’Leary et al. (2012) & $\begin{array}{l}\text { Média de duração do casamento: } 21,40 \text { anos } \\
\text { para mulheres e } 20,23 \text { para homens. }\end{array}$ & Quali & $\begin{array}{l}\text { Amostra composta por } 274 \text { entrevistados } \\
\text { casados e uma amostra de Nova Iorque com } \\
396 \text { cônjuges. }\end{array}$ \\
\hline Landis et al. (2013) & $\begin{array}{l}\text { Duração variou de } 25 \text { a } 57 \text { anos; média de } \\
42 \text { anos de duração. }\end{array}$ & Quanti & $\begin{array}{l}132 \text { casais em casamentos de longa duração, } \\
\text { com idade mínima de } 67 \text { e máxima de } 95 \text { anos. }\end{array}$ \\
\hline Proulx et al. (2013) & Duração média do casamento de 33,1 anos. & Misto & $\begin{array}{l}707 \text { adultos casados com média de idade de } \\
55,7 \text { anos. }\end{array}$ \\
\hline Sabey et al. (2014) & Duração média do casamento de 42 anos. & Quanti & $\begin{array}{l}64 \text { casais heterossexuais, com média de idade } \\
\text { de } 70 \text { anos. }\end{array}$ \\
\hline Donoho et al. (2015) & Duração média do casamento de 10 anos. & Quanti & $\begin{array}{l}\text { Amostra de casais de meia idade e idosos } \\
\text { extraídos do Estudo de Biomarcadores } \\
\text { MIDUS. }\end{array}$ \\
\hline Perrig-Chiello et al. (2015) & $\begin{array}{l}\text { Duração do casamento variou de } 15 \text { a } 40 \text { anos; } \\
\text { média de } 23,62 \text { anos de duração. }\end{array}$ & Quanti & $\begin{array}{l}308 \text { participantes, sendo } 113 \text { homens e } \\
195 \text { mulheres. }\end{array}$ \\
\hline Costa et al. (2015a) & Duração do casamento variou de 20 a 32 anos. & Quali & $\begin{array}{l}200 \text { pessoas com idade mínima de } 40 \text { anos e } \\
\text { máxima de } 57 \text { anos. }\end{array}$ \\
\hline Costa et al. (2015b) & Duração do casamento variou de 20 a 32 anos. & Quali & $\begin{array}{l}\text { Cinco mulheres e quatro homens que } \\
\text { viviam em união estável, porém, não unidos } \\
\text { maritalmente entre si, com idades entre } \\
40 \text { e } 57 \text { anos. }\end{array}$ \\
\hline Costa et al. (2015c) & $\begin{array}{l}\text { Estudo quanti: a duração média do casamento } \\
\text { foi de } 18,26 \text { anos. } \\
\text { Estudo quali: a duração do casamento variou } \\
\text { de } 20 \text { a } 32 \text { anos. }\end{array}$ & Misto & $\begin{array}{l}200 \text { participantes com média de idade de } \\
41,81 \text { anos, variando de } 22 \text { a } 66 \text { anos. } \\
\text { No estudo quali, participaram nove pessoas, } \\
\text { com idade mínima de } 40 \text { anos. }\end{array}$ \\
\hline Grizólio et al. (2015) & $\begin{array}{l}\text { Duração do casamento variou de } 32 \text { a } 53 \text { anos; } \\
\text { média de } 39,5 \text { anos de duração. }\end{array}$ & Quali & 25 casais, com média de idade de 64,1 anos. \\
\hline Haase et al. (2016) & $\begin{array}{l}\text { Casais de longa duração, o estudo não } \\
\text { especificou o tempo de duração do casamento. }\end{array}$ & Quanti & $\begin{array}{l}156 \text { casais divididos em um grupo de } \\
\text { meia-idade ( } 40 \text { a } 50 \text { anos) e um de maior idade } \\
(60-70 \text { anos). }\end{array}$ \\
\hline Alves-Silva et al. (2017) & $\begin{array}{l}\text { Duração média do casamento variou de } 32 \text { a } \\
66 \text { anos; média de } 47,7 \text { anos de duração. }\end{array}$ & Quali & $\begin{array}{l}\text { Sete cônjuges em casamentos de longa } \\
\text { duração. }\end{array}$ \\
\hline Campos et al. (2017) & $\begin{array}{l}\text { Duração média do casamento variou de } 32 \text { a } \\
53 \text { anos; média de } 39,5 \text { anos de duração. }\end{array}$ & Quali & 25 cônjuges em casamentos de longa duração. \\
\hline Silva et al. (2017) & $\begin{array}{l}\text { Duração média do casamento variou de } 32 \text { a } \\
53 \text { anos; média de } 39,5 \text { anos de duração. }\end{array}$ & Quali & $\begin{array}{l}25 \text { casais heterossexuais em casamentos de } \\
\text { longa duração. }\end{array}$ \\
\hline
\end{tabular}


Acevedo e Aron (2009) alertam sobre o risco de utilizar amostras pouco representativas, visto que amostras culturalmente diversas evitaria viés de seleção, isto é, possibilitariam que os resultados não fossem influenciados pela seleção de participantes, muitas vezes feita por conveniência e constituída prioritariamente de indivíduos brancos, saudáveis, felizes e expoentes de valores ocidentais.

Nota-se que a maioria dos estudos foi desenvolvida em outros países, fundamentada em abordagem metodológica majoritariamente quantitativa, com amostra predominantemente idosa e com duração mínima do casamento de sete anos (Sardinha et al., 2009) e máxima de 65 anos (Rosowsky et al., 2012). Observa-se também que o periódico estrangeiro mais utilizado para publicação de estudos sobre casamento de longa duração foi o Journal of Family Psychology e no âmbito nacional a revista Psicologia em Estudo (Maringá), que tem como política editorial a publicação de estudos eminentemente qualitativos.

Os resultados foram organizados e apresentados em categorias temáticas, definidas a posteriori em função da proximidade de conteúdos e/ou convergência dos dados. Da Categoria 1 (Satisfação conjugal e beneficios para a saúde) fazem parte os estudos de Berg et al. (2011), Donoho et al. (2015), Gestorf et al. (2009), Haase et al. (2016), Landis et al. (2013), Petrican et al. (2011), Proulx e Snyder-Rivas (2013) e Sandberg et al. (2009). Na Categoria 2 (Amor e sexualidade em casamentos de longa duração) encontram-se as pesquisas de Alves-Silva et al. (2017), Campos et al. (2017), Elliott e Umberson (2008), O'Leary et al. (2012) e Sabey et al. (2014). Na Categoria 3 (Conflito conjugal e estratégia de enfrentamento) foram agrupados os estudos de Costa e Mosmann (2015a, 2015b), Costa et al. (2015c), Landis et al. (2013), Mazzoleni et al. (2009), Perrig-Chiello et al. (2015) e Silva et al. (2017). A Categoria 4 (Suporte social, família e habilidades dos cônjuges) inclui as pesquisas de Alves-Silva et al. (2017), Berg et al. (2011), Grizólio et al. (2015), Landis et al. (2013), Rosowsky et al. (2012) e Sardinha et al. (2009). Os estudos de Alves-Silva et al. (2017), Berg et al. (2011) e Landis et al. (2013) foram considerados em mais de uma categoria.

\section{Categoria 1: Satisfação conjugal e benefícios para a saúde}

No estudo de Landis et al. (2013), a satisfação com o casamento é considerada altamente relevante para a saúde física e psicológica dos cônjuges, especialmente na velhice, o que contribui para a funcionalidade do relacionamento que, por sua vez, favorece a estabilização da saúde. No entanto, o estudo aponta que nem sempre o casamento confere benefícios, uma vez que vínculos conjugais de baixa qualidade podem ser preditores de depressão, problemas de saúde e dissolução conjugal, além de fazer declinar a autopercepção da saúde. Esses autores ressaltam ainda que as dinâmicas emocionais e sociais de interação exigem uma adaptação permanente do casal às potenciais fontes de estresse. Por essa razão, comportamentos de apoio e interações positivas dos cônjuges foram percebidos como fatores extremamente relevantes a longo prazo.

O estudo de Haase et al. (2016) fornece evidências de que os comportamentos de raiva e esquiva, expressões comuns durante o conflito conjugal, podem prever sintomas cardiovasculares e musculoesqueléticos, respectivamente, considerados problemas relevantes de saúde pública. Tal fato corrobora os resultados reportados pelo estudo de Donoho et al. (2015) que, preocupados com a qualidade da relação conjugal e a sua associação com problemas cardiovasculares, mostraram que, mesmo em uniões de longa duração relativamente estáveis, pequenas variações na qualidade do relacionamento podem estar associadas com a saúde cardiovascular. Além disso, percebeu-se que indivíduos recasados têm menor variabilidade da frequência cardíaca do que aqueles que permanecem continuamente casados, o que sugere que rupturas conjugais ou viuvez podem ter efeitos duradouros sobre a saúde cardiovascular.

Já Gerstorf et al. (2009) e Petrican et al. (2011) preocuparam-se em investigar o funcionamento cognitivo dos idosos. O primeiro estudo constatou que o desempenho dos maridos em relação às medidas de velocidade perceptual e processamento da memória precede e prevê as mudanças subsequentes nas mesmas medidas nas esposas. No entanto, foi constatada evidência limitada para o padrão unidirecional oposto, ou associação bidirecional, o que pode ser pensado como consequência das diferenças de gênero que são reproduzidas na díade conjugal. Ou seja, lança-se mão da hipótese de que recursos adicionais dos maridos, como uma vida profissional exigente, ou até mesmo expectativas de controle e domínio mais acentuadas, influenciariam seus desempenhos cognitivos.

O estudo de Petrican et al. (2011) debruçou-se sobre o fenômeno de controle de olhar fixo, uma característica adaptativa na idade adulta, tanto entre os cônjuges idosos saudáveis, quanto em idosos que apresentam condições crônico-degenerativas. Observou-se que, entre os cônjuges idosos saudáveis, o controle do olhar fixo superior previu um funcionamento sociocognitivo superior, ao passo que aqueles que tinham habilidades mais pobres foram percebidos pelo parceiro como um estreitamento da percepção de sua autonomia, 
prevendo menor satisfação e declínio da qualidade da relação conforme aumenta a incapacidade do paciente.

Dada a relação entre conflito conjugal e problemas de saúde, o estudo de Sandberg et al. (2009) constatou que cônjuges felizes no casamento são mais propensos a usar os serviços de saúde, haja vista que se beneficiam dessa maior frequência nos ambientes de cuidados por meio do incentivo para procurarem ajuda médica. Em casamentos considerados problemáticos, ambos os cônjuges são menos propensos a buscar cuidados, o que pode se tornar um problema de saúde pública, prejudicando a definição precoce de diagnósticos e intervenções. Tais aspectos vão ao encontro do estudo de Proulx e Snyder-Rivas (2013), que consideram o casamento uma dimensão de potencial intervenção na concepção de promoção da saúde ou plano de tratamento. Assim, a qualidade conjugal está associada ao bem-estar do parceiro, constituindo uma medida sensível de mudanças na saúde dos cônjuges.

\section{Categoria 2: Amor e sexualidade em casamentos de longa duração}

De acordo com o estudo de Sabey et al. (2014), o amor compassivo, definido como um amor centrado no bem do outro e ligado à religiosidade e santificação do casamento, aumenta a satisfação e a estabilidade conjugal, sendo um ingrediente importante para a manutenção do casamento. Assim, esse tipo de amor pode ser fortalecido na velhice, especialmente devido à crescente preocupação com a saúde entre os idosos, podendo inspirar os casais a enfrentarem o desafio de cuidarem um do outro, colocando-se a serviço da manutenção da qualidade de seu relacionamento. Para os autores, o amor compassivo pode ser benéfico para incrementar a própria visão que se tem sobre o casamento, inspirando um tipo de vínculo altruísta que fornece incentivo e motivação, e prioriza as necessidades do cônjuge sobre as próprias.

Em relação ao papel da sexualidade nos casamentos longevos, o estudo de Campos et al. (2017) aponta que as transformações da conjugalidade de longa duração envolveram a diminuição da frequência sexual e uma modificação naquilo que os cônjuges valorizam como intimidade. O desejo sexual passa, então, a ser encarado de maneira diferente em função da idade, de processos maturacionais e do adoecimento, o que abre espaço para uma sexualidade vivida de maneira mais ampla, a partir da ressignificação do afeto, da presença e dos sentimentos do casal. Esses aspectos corroboram o estudo de O'Leary et al. (2012), que observaram que adultos mais velhos não relataram ter mantido relação sexual no último ano, indicando que, mesmo assim, podem se sentir intensamente apaixonados desde que o afeto seja perene. Assim, o desejo e o afeto mostram ser fatores-chave nos quais os casais podem se concentrar e a partir dos quais podem experimentar fortes sentimentos positivos.

Ainda nesse contexto, no estudo de Alves-Silva et al. (2017) a sexualidade não foi expressa de forma direta nos relatos individuais e nas entrevistas com os casais em conjunto, o que, segundo a autora, revela uma possibilidade de que a atividade sexual não é considerada atributo necessário para garantir os casamentos de longa duração. A pesquisa realizada por O'Leary et al. (2012) ainda traz a perspectiva de casais idosos que permanecem em um casamento satisfatório, quando relatam que ainda estão apaixonados e mantêm interesses comuns. Eles não se queixam de serem frequentemente assolados por pensamentos intrusivos, que podem ser corriqueiros entre aqueles que experimentam a paixão.

Diferentemente dessas perspectivas, Elliott e Umberson (2008) observaram em suas pesquisas que, na cultura contemporânea, a atividade sexual é cada vez mais valorizada como desejável, senão obrigatória, para garantir a harmonia conjugal, o que indica que a satisfação conjugal está significativamente associada à satisfação sexual. Segundo os autores, experimentar o desejo sexual desigual se torna uma fonte de conflito potencial para os casais, principalmente no que diz respeito à frequência da atividade sexual. Assim, as mulheres tenderiam a se esforçar para desejar ter relações sexuais com mais frequência, enquanto os homens se empenham para reduzir seus desejos e se concentrar na qualidade do sexo. Além disso, maridos podem usar o trabalho doméstico e o envolvimento emocional como uma tentativa de aumentar a frequência das relações sexuais, enquanto que as esposas veem a atividade sexual como uma espécie de terceiro turno, ou seja, mais uma obrigação no rol do já extenso cotidiano feminino.

\section{Categoria 3: Conflito conjugal e estratégias de enfrentamento}

Segundo Costa et al. (2015c), durante o relacionamento conjugal são esperadas possíveis divergências, e a maioria dos casais enfrenta conflitos muito semelhantes, que são considerados comuns no cotidiano do casamento. As questões que podem provocar desentendimentos referem-se a problemas quanto à educação e comportamento dos filhos, à saída tardia dos mesmos da casa dos pais, às experiências vivenciadas na família de origem, principalmente o vínculo e a interferência da família das esposas, as finanças, sobretudo os problemas como desemprego, falta de dinheiro, sobrecarga sobre o cônjuge que arca 
com as despesas sozinho, problemas na administração das finanças domésticas e o fato de a mulher ganhar mais do que o marido ou não trabalhar fora. No entanto, as autoras consideram que os conflitos, além de esperados, indicam um processo de amadurecimento conjugal no qual os parceiros tentam negociar suas diferenças e ajustá-las, de modo a tornar a conjugalidade satisfatória para ambos.

Costa et al. (2015c) relatam ainda os efeitos produzidos pelos conflitos que são majoritariamente negativos, suscitando ansiedade, raiva, mágoa e indignação nos cônjuges, podendo se intensificar caso o problema não seja resolvido. Além disso, se externalizados sem o devido autocontrole, poderão provocar consequências negativas mais sérias do que o próprio motivo do conflito, além de reações psicológicas e fisiológicas nos parceiros. Esses resultados corroboram o estudo de Mazzoleni et al. (2009), que se concentrou nos efeitos do conflito conjugal em esposas de jogadores patológicos. Segundo esse estudo, o casamento, permeado por brigas constantes, apresenta baixa qualidade conjugal e gera grande insatisfação, principalmente por parte das esposas, que estão sempre sob intensa aflição e necessitadas de apoio.

Costa e Mosmann (2015b) apontam que existem estratégias de resolução construtivas (como conversar pacificamente, manter a calma, avaliar as consequências do que será dito ao parceiro); destrutivas (comportamentos de retaliação, ser impulsivo, irritarse, impor que o outro mude seu jeito de ser, desistir da situação), além de comportamentos que interferem nas estratégias de resolução dos conflitos adotadas (egoísmo, arrogância, orgulho e inflexão). No entanto, com o passar dos anos, porque se adquire maturidade e/ou por tentativa e erro, o casamento vai se tornando uma experiência mais estável, sem tantos altos e baixos (Costa \& Mosmann, 2015a). Nessa vertente, Costa e Mosmann (2015b) apontam que os parceiros parecem ficar mais tolerantes, compreensíveis e flexíveis, aperfeiçoando suas capacidades de reconhecer as próprias fraquezas, interpretar as situações de conflito e de gerenciar as turbulências que podem permear o casamento, o que possibilita desenvolver ou aperfeiçoar suas habilidades de enfrentamento. Isso pode significar uma mudança de postura diante dos problemas conjugais.

No estudo de Silva et al. (2017) os casais afirmaram que a chave para o enfrentamento das divergências está no exercício cotidiano da paciência, aceitação, compreensão e, por vezes, renúncia e resignação. A aprendizagem e o exercício da compreensão ocorrem na própria vivência da rotina conjugal, que contribui para o desenvolvimento da intimidade que pode atuar na prevenção de conflitos, favorecendo uma reflexão individual por parte dos cônjuges. Isso permite que o parceiro se autoavalie e pondere suas próprias atitudes e comportamentos, deixando de culpabilizar o outro para se perceber como corresponsável pelo cenário atual do relacionamento.

Nesse contexto, o estudo de Landis et al. (2013) define o enfrentamento diádico bem-sucedido, como uma habilidade funcional que ajuda a amortecer o impacto das situações estressantes e qualifica, assim, o caminho que o casal escolhe para lidar com o estresse que afeta um dos parceiros ou ambos. Além disso, os autores mostraram que o apoio ao enfrentamento diádico dos cônjuges mais velhos foi significativamente associado com maior satisfação com o relacionamento, o que mostra a importância da qualidade da interação do casal. No entanto, quando não se encontram estratégias adequadas para superar o conflito, muitos casais veem o divórcio como única opção.

O estudo de Perrig-Chiello et al. (2015) revelou que a maioria das pessoas divorciadas, após um casamento de longa duração, tende a se adaptar muito bem. Apesar desse bom ajustamento, obtido por meio de seus recursos intrapessoais e da resiliência, a separação em uma idade avançada e após um relacionamento de longo prazo é associada a sentimentos de resignação, possivelmente devido a um leque mais limitado de recursos e opções disponíveis.

\section{Categoria 4: Suporte social, família e habilidades dos cônjuges}

Berg et al. (2011) descreveram a importância do cônjuge na velhice e consideraram a colaboração diádica como um fator fundamental para o relacionamento conjugal, na medida em que leva o casal a trabalhar em conjunto para tomar decisões diárias e resolver problemas cotidianos. Assim, em relacionamentos interpessoais próximos, como os que frequentemente se encontram nos casamentos de longa duração, a colaboração e o apoio conferido pelo parceiro íntimo têm sido descritos como fatores-chave para o bom funcionamento conjugal, influenciando inclusive o nível de satisfação dos cônjuges.

O parceiro íntimo figura como fonte de apoio social importante por várias razões. Em primeiro lugar, a velhice é uma etapa do ciclo vital que comporta várias mudanças que afetam, paulatinamente, a funcionalidade das pessoas. Além disso, a morte de amigos e a eventual perda do parceiro íntimo podem levar a um estreitamento das redes sociais, o que, consequentemente, aumenta a relevância do parceiro como fonte de apoio social. Em segundo lugar, os recorrentes problemas de saúde podem limitar o acesso 
a outros sistemas de apoio social. Em terceiro lugar, depois de longos anos dedicando-se ao trabalho e ao exercício da função parental, o foco se volta novamente à díade conjugal (Landis et al., 2013).

Como apontam Grizólio et al. (2015), devido à relevância das redes de apoio social, a família e a presença dos filhos ganham destaque na velhice. A importância atribuída aos filhos em casamentos de longa duração é quase uma unanimidade e ocupa um espaço muito importante na vida do casal. No entanto, para os autores, a existência de filhos não parece ser o fator que mantém a integridade do casamento, aparecendo mais como um aspecto que protegeria os genitores da solidão, gerando uma rede de apoio constante dentro do próprio lar.

Em todo casamento, principalmente nos de longa duração, é importante que o cônjuge seja provido de certas qualidades ou características para que o casamento perdure de maneira satisfatória, aspectos investigados por Alves-Silva et al. (2017), Rosowsky et al. (2012) e Sardinha et al. (2009). Para esses últimos autores, a empatia se relaciona significativamente com todos os aspectos da satisfação conjugal, na medida em que, quando um parceiro procura ver os fatos sob a ótica do outro, muitos atritos podem ser evitados e encontrar uma solução satisfatória para os problemas se torna mais fácil. Rosowsky et al. (2012) consideram que as dimensões de personalidade dos cônjuges também contribuem para a presença ou ausência de satisfação conjugal. O estudo de Sardinha et al. (2009) mostrou que o número de filhos é inversamente relacionado à qualidade da interação conjugal. Assim, supõe-se que o estresse desencadeado pela necessidade de prover cuidados parentais a uma prole maior pode demandar mais esforços adaptativos e habilidades de enfrentamento dos cônjuges.

\section{Discussão}

A satisfação conjugal tem sido considerada como um fator relevante para a manutenção da afetividade entre os cônjuges durante os anos de relacionamento. É importante lembrar que a satisfação conjugal é um construto que não se refere somente ao casal, estendendo-se também ao plano individual, pois cada um pode ter uma maneira diferente de considerar o que é ou não satisfatório em um relacionamento (Alves-Silva et al., 2016). Essa dimensão emergiu como significativa para os casamentos de longa duração, podendo ser preditora de saúde, resultando na manutenção do relacionamento ao longo dos anos, e na busca dos cônjuges por serviços de saúde. Já os vínculos conjugais de baixa qualidade estão relacionados a problemas de saúde, tais como depressão, sintomas cardiovasculares e muscoesqueléticos, e menor funcionamento cognitivo do cônjuge, o que pode ser observado nos estudos da Categoria 1. Esses aspectos corroboram os achados obtidos por Marques e Souza (2012) em estudo que evidenciou que um alto nível de satisfação conjugal pode se tornar particularmente importante para os casamentos de longo prazo, visto que adultos mais velhos apresentam maior risco de ter problemas de saúde.

A busca por relacionamentos significativos faz o indivíduo experimentar sentimentos de amor e intimidade, sendo o casamento uma possibilidade apreciada e cultivada em nossa cultura, seja pela profundidade do vínculo e da intimidade que propicia, seja pelos sentimentos de companhia e autoafirmação alimentados pela relação estabelecida com o parceiro (Melo et al., 2014). Como observado nos estudos da Categoria 2, o amor e a sexualidade no decorrer dos anos tendem a ser percebidos de forma mais ampliada, uma vez que ocorre uma ressignificação do afeto e a companhia e a presença do outro passam a ser mais valorizadas do que a relação sexual. As amostras utilizadas nos estudos evidenciaram que grande parte dos casais é constituída por idosos e, por isso, o exercício da sexualidade passa a ser influenciado pelo processo de envelhecimento ou pela decadência da condição de saúde dos cônjuges. Assim, foi um dado comum aos diversos estudos que, ou a relação sexual ocorre com menor frequência, enquanto outros aspectos passam a ser mais valorizados, ou os participantes não falam a respeito dessa temática, um silenciamento cujo significado precisa ser melhor compreendido. Apenas um artigo ressalta claramente a sexualidade como um componente fundamental para a manutenção do casamento e discute as implicações do desejo sexual desigual entre os cônjuges.

No estudo de Strey et al. (1999) foi possível encontrar resultados parecidos. Em sua amostra de casais longevos, apesar de as relações sexuais não serem mais tão frequentes quanto eram no passado, eles relataram que se sentiam satisfeitos em relação às práticas atuais. As autoras ressaltaram a influência dos limites do processo de envelhecimento e possíveis adoecimentos, além de relatarem que, com o passar dos anos, os cônjuges tendem a ficar mais companheiros e compartilhar mais interesses em comum. Logo, ao longo do relacionamento parece haver uma mudança de foco, na qual o sexo deixa de ser tão importante na hierarquia das necessidades do casal, passando sua vez para a amizade. Os resultados do estudo de Arias e Pollizi (2013) evidenciaram o elevado investimento que o casal dedica ao casamento, dada a 
sua importância presumida, principalmente na velhice, pois, para os participantes, é esse relacionamento que proporciona companheirismo, apoio, assistência mútua e o compartilhamento de toda a rotina doméstica ou de grande parte das atividades diárias.

A partir dos resultados encontrados na Categoria 3 , observou-se que alguns conflitos são comuns ao cotidiano dos casamentos em geral, como a educação e criação dos filhos e os aspectos financeiros. No entanto, na medida em que o relacionamento avança, outras questões vêm à tona, principalmente devido à inserção de familiares em diferentes etapas do ciclo vital. Além disso, com o passar dos anos, os conflitos tendem a arrefecer e diminuir de importância, uma vez que os cônjuges parecem se adaptar um ao outro, apresentando estratégias funcionais no cotidiano conjugal, tais como a compreensão mútua e o exercício da tolerância e paciência no jogo relacional. Esses achados estão relacionados com um aspecto abordado no estudo de Mosmann e Falcke (2011), que sugere a existência de problemas típicos do início do casamento, enquanto outros surgem ao longo do ciclo vital. De acordo com as autoras, o conflito conjugal pode ser considerado um acontecimento no qual os cônjuges divergem, caracterizando-se como mais ou menos grave pela frequência e intensidade com que ocorre, e também por seu conteúdo e pelas estratégias de resolução utilizadas pelo casal.

Esses dados encontram ressonância na revisão da literatura realizada por Costa, Cenci e Mosmann (2016), cujos resultados mostraram que, nos primeiros anos de casamento, os conflitos podem ser mais intensos, frequentes e difíceis de se resolverem, por se tratar de um período de adaptação entre os cônjuges que demanda maior esforço, investimento e apoio entre os parceiros. Findo esse período, é possível que os cônjuges compreendam que a vida conjugal e familiar exige investimento mútuo e esforço constante, e que certas situações não serão resolvidas de acordo com suas expectativas. Assim, considera-se que as diferenças e desacordos conjugais são naturais e até mesmo fundamentais para o desenvolvimento da conjugalidade, o que é diferente das brigas, que tendem a ter efeitos negativos, tais como ansiedade, raiva e mágoa.

Os resultados mostraram que, quando se trata de casamentos de longa duração, a amostra de casais normalmente se encontra entre a meia-idade e a velhice, e esse público, especialmente os mais velhos, já manifestam alguns prejuízos devido ao avanço da idade. Segundo Marques e Sousa (2012), as relações familiares e conjugais na velhice são marcadas pela reestruturação de papéis, visto que o retorno ao modelo de díade conjugal impõe a reorganização de tarefas e atribuições na vida de cada cônjuge. $\mathrm{Na}$ Categoria 4, é possível encontrar artigos que relatam a importância de se contar com uma rede de apoio, oferecido principalmente pelo parceiro íntimo, mas também pela família, filhos, vizinhos e amigos, corroborando o estudo de Areosa et al. (2012), que considera o apoio social um fator importante para que a pessoa com mais idade possa manter-se ativa, com autonomia preservada, logrando um envelhecimento satisfatório, sem ser exposta a tantos efeitos negativos. Segundo os autores, a família constitui-se como fonte de apoio e ajuda de maior importância, assim como os amigos e vizinhos, mas, mesmo assim, o cônjuge aparece como elemento preferido pela díade conjugal e somente quando ele vem a faltar busca-se o apoio externo.

Para Ramos (2002), o acesso às redes de apoio também reduz significativamente os efeitos deletérios do estresse nos indivíduos mais velhos, oferecendo suporte social na forma de amor, afeição, preocupação e assistência. Talvez se possa pensar que o ato de oferecer suporte a alguém demonstra, além de preocupação, uma gama de outros sentimentos que têm por base o altruísmo e que envolvem o cuidado e o querer bem ao outro, e esses aspectos podem ser essenciais para a manutenção de um relacionamento de longa duração. Além disso, para que o casamento perdure é importante que o cônjuge disponha de qualidades e características tais como empatia, respeito e consideração pelo(a) parceiro(a), para que eles possam trilhar um caminho juntos.

\section{Considerações finais}

Por meio do conhecimento, mapeamento e sintetização da atual produção científica acerca do casamento de longa duração, e retomando a questão inicial que motivou o presente estudo - sobre como os casamentos de longa duração têm sido abordados na literatura científica nacional e internacional identificou-se, a partir do corpus coligido, a presença de variáveis relevantes para a manutenção do casamento.

Os principais aspectos identificados foram a satisfação conjugal e os benefícios que ela confere ao casamento, como o aumento da qualidade conjugal e a repercussão positiva na saúde física e psíquica dos cônjuges. Nos casamentos de longa duração, a sexualidade é vista como desejável, senão como um requisito obrigatório para garantir a harmonia conjugal, além de ser percebida de diferentes maneiras entre os cônjuges. Já o amor é visto como essencial para a manutenção do matrimônio e o seu desaparecimento é consistentemente evocado como motivo para o 
divórcio. Assim, ao contrário do que afirma o senso comum, o amor persiste em casamentos longevos; no entanto, modifica-se ao longo do tempo.

Conflitos conjugais também foram retratados na literatura dos casamentos de longo prazo, no entanto, apesar de seus efeitos serem majoritariamente negativos, podem indicar um processo de amadurecimento pessoal e tendem a diminuir com o passar dos anos. Por isso, é importante criar estratégias saudáveis de enfrentamento para lidar com as divergências, sendo interessante que o casal disponha de certas habilidades bem desenvolvidas, como a capacidade empática, para que o casamento se mantenha em um nível satisfatório para ambos os cônjuges.

A perspectiva da velhice também foi assunto recorrente na literatura, sendo mostrada como uma fase da trajetória desenvolvimental permeada por mudanças significativas que podem impactar a vida das pessoas. Aposentadoria, saída dos filhos de casa, morte dos amigos e até mesmo a perda do cônjuge, além da crença perpetuada por nossa cultura de que os idosos não contribuem mais para a sociedade, fazem desse estágio um período de difícil adaptação. Por isso, nos casamentos longevos, nos quais os cônjuges são idosos, percebe-se uma necessidade de maior apoio social, a qual pode ser suprida pelo próprio parceiro ou por outros familiares.

Considerando que as escolhas metodológicas que orientaram a busca bibliográfica do presente estudo podem ter limitado o acesso a um corpus substancialmente maior, para as próximas revisões pode ser interessante recuperar materiais que ainda não tenham sido publicados em formato de artigos, tais como teses, dissertações, capítulos e livros, a fim de verificar a existência de outras produções não localizadas a partir do método da revisão integrativa. Por se tratar de uma revisão que recuperou estudos que focalizam majoritariamente realidades de outros países, é relevante conduzir novos estudos em âmbito nacional, uma vez que as amostras utilizadas são suscetíveis de viés cultural. A partir dos achados abrese a possibilidade de investigar de modo mais detido aspectos como sexualidade, gênero e religiosidade/ espiritualidade nesse público, adensando o repertório de conhecimentos sobre os casais longevos, suas características e modos de viver, uma vez que tais assuntos foram pouco abordados nos artigos recuperados na presente revisão.

\section{Referências}

Acevedo, B. P. \& Aron, A. (2009). Does a long-term relationship kill romantic love? Review of General Psychology, 13(1), 59-65. https://doi.org/10.1037/a0014226

Alves-Silva, J. D., Scorsolini-Comin, F., \& Santos, M. A. (2017). Bodas para uma vida: Motivos para manter um casamento de longa duração. Temas em Psicologia (Ribeirão Preto), 25(2), 487-501. https://doi.org/10.9788/ tp2017.2-05

Alves-Silva, J. D., Scorsolini-Comin, F., \& Santos, M. A. (2016). Conjugalidade e casamento de longa duração na literatura científica. Contextos Clínicos, 9(1), 32-50. https://doi.org/10.4013/ctc.2016.91.03

Amorim, A. N. \& Stengel, M. (2014). Relações customizadas e o ideário de amor na contemporaneidade. Estudos de Psicologia (Natal), 19(3), 157-238. https://doi.org/10.1590/s1413-294x2014000300003

Areosa, S. V. C., Benitez, L. B., \& Wichmann, F. M. A. (2012). Relações familiares e o convívio social entre idosos. Textos \& Contextos, 11(1), 184-192. (DOI INEXISTENTE)

Arias, C. J. \& Polizzi, L. (2013). The couple relationship: support functions and sexuality in old age. Journal Kairós Gerontologia, 16(1), 27-48.

Bachand, L. L. \& Caron, S. L. (2001). Ties that bind: a qualitative study of happy long-term marriages. Contemporary Family Therapy, 23(1), 105-121. https://doi.org/10.1023/A:1007828317271

Berg, C. A., Schindler, I., Smith, T. W., Skinner, M., \& Beveridge, R. M. (2011). Perceptions of the cognitive compensation and interpersonal enjoyment functions of collaboration among middle-aged and older married couples. Psychology and Aging, 26(1), 167-173. https://doi.org/10.1037/a0021124

Campos, S. O., Scorsolini-Comin, F., \& Santos, M, A. (2017). Transformações da conjugalidade em casamentos de longa duração. Psicologia Clínica, 29(1), 69-89. https://doi.org/10.4025/psicolestud.v20i4.29536

Costa C. B., Cenci, C. M. B., \& Mosmann, C. P. (2016). Conflito conjugal e estratégias de resolução: uma revisão sistemática da literatura. Temas em Psicologia, 24(1), 325-338. https://doi.org/10.9788/tp2016.1-22 
Costa, C. B. \& Mosmann, C. P. (2015a). Relacionamentos conjugais na atualidade: percepções de indivíduos em casamentos de longa duração. Revista da SPAGESP, 16(2), 16-31. https://doi.org/10.4025/psicolestud.v20i3.27817

Costa, C. B. \& Mosmann, C. P. (2015b). Estratégias de resolução dos conflitos conjugais: percepções de um grupo focal. Psico (Porto Alegre), 46(4), 472-482. https://doi.org/10.15448/1980-8623.2015.4.20606

Costa, C. B., Falcke, D., \& Mosmann, C. P. (2015c). Conflitos conjugais em casamentos de longa duração: motivos e sentimentos. Psicologia em Estudo (Maringá), 20(3), 411-423. https://doi.org/10.4025/psicolestud.v20i3.27817

Donoho, C.J., Seeman, T. E., Sloan, R. P., \& Crimmins, E. M. (2015). Marital status, marital quality, and heart rate variability in the MIDUS cohort. Journal of Family Psychology, 29(2), 290-295. https://doi.org/10.1037/fam0000068

Elliott, S. \& Umberson, D. (2008). The performance of desire: gender and sexual negotiation in long-term marriages. Journal Marriage Family, 70(2), 391-406. https://doi.org/10.1111/j.1741-3737.2008.00489.x

Féres-Carneiro, T. (2003). Separação: o doloroso processo de dissolução da conjugalidade. Estudos em Psicologia (Natal), 8(3), 367-374. https://doi.org/10.1590/s1413-294x2003000300003

Féres-Carneiro, T. \& Diniz-Neto, O. (2010). Construção e dissolução da conjugalidade: padrões relacionais. Paidéia (Ribeirão Preto), 20(46), 269-378. https://doi.org/10.1590/s0103-863x2010000200014

Garcia, M. L. T. \& Tassara, E. T. O. (2001). Estratégias de enfrentamento do cotidiano conjugal. Psicologia: Reflexão e Crítica, 14(3), 635-642. https://doi.org/10.1590/s0102-79722001000300019

Gerstorf, D., Anstey, K. J., Hoppmann, C. A., \& Luszcz, M. A. (2009). Dynamic links of cognitive functioning among married couples: longitudinal evidence from the Australian longitudinal study of ageing. Psychology and Aging, 24(2), 296-309. https://doi.org/10.1037/a0016649

Grizólio, T. C., Scorsolini-Comin, F., \& Santos, M. A. (2016). A percepção da parentalidade de cônjuges engajados em casamentos de longa duração. Psicologia em Estudo (Maringá), 20(4), 663-674. https://doi.org/10.4025/ psicolestud.v20i4.29536

Haase, C. M., Holey, S., Block, L., Verstaen, A., \& Levenson, R. W. (2016). Interpersonal emotional behaviors and physical health: a 20-year longitudinal study of long-term married couples. Emotion, 16(7), 965-977. https://doi. org/10.1037/a0040239

Instituto Brasileiro de Geografia e Estatística [IBGE]. (2013). Estatística do registro civil. Rio de Janeiro: Autor. https://doi.org/10.17143/ciaed/xxiilciaed.2017.00322

Landis, M., Peter-Wight, M., Martin, M., \& Bodenmann, G. (2013). Dyadic coping and marital satisfaction of older spouses in long-term marriage. GeroPsych, 26(1), 39-47. https://doi.org/10.1024/1662-9647/a000077

Marques, F. \& Sousa, L. (2012). Agregado familiar de casais idosos: estrutura, dinâmicas e valores. Revista Temática Kairós Gerontologia, 15(1), 177-198. (DOI INEXISTENTE)

Mazzoleni, M. H. B., Gorenstein, C., Fuentes, D., \& Tavares, H. (2009). Esposas de jogadores patológicos: traços de personalidade, sintomas depressivos e ajustamento social. Revista Brasileira de Psiquiatria, 31(4), 332-337. https://doi.org/10.1590/s1516-44462009005000009

Melo, C. F., Leite, C., Santos, F. O., Gontijo, J., \& Souza, T. M. (2014). Vou pedir sua mão... mas o que eu faço com ela? Conjugalidade e psicanálise. Reverso, 36(68), 27-31. (DOI INEXISTENTE)

Mendes, K. D. S., Silveira, R. C. C. P., \& Galvão, C. M. (2008). Revisão integrativa: método de pesquisa para a incorporação de evidências na saúde e na enfermagem. Texto \& Contexto Enfermagem, 17(4), 758-764. https://doi.org/10.1590/s0104-07072008000400018

Mosmann, C. P. \& Falcke, D. (2011). Conflitos conjugais: motivos e frequência. Revista da SPAGESP, 12(2), 5-16. (DOI INEXISTENTE)

Norgren, M. B., Souza, R. M., Kaslow, F., Hammerschmidt, H., \& Sharlin, S. A. (2004). Satisfação conjugal em casamentos de longa duração: uma construção possível. Estudos de Psicologia (Natal), 9(3), 575-584. https://doi.org/10.1590/s1413-294x2004000300020

O'Leary, K. D., Acevedo, B. P., Aron, A., Huddy, L., \& Mashek, D. (2012). Is long-term love more than a rare phenomenon? If so, what are its correlates? Social Psychological and Personality Science, 3(2), 241-249. https://doi.org/10.1177/1948550611417015

Perrig-Chiello, P., Hutchison, S., \& Morselli, D. (2015). Patterns of psychological adaptation to divorce after a long-term marriage. Journal of Social and Personal Relationships, 32(3), 386-405. https://doi. org/10.1177/0265407514533769 
Petrican, R., Bielak, T., Schimmack, U., \& Moscovitch, M. (2011). For my eyes only: gaze control, enmeshment and relationship quality. Journal of Personality and Social Psychology, 100(6), 1111-1123. https://doi.org/10.1037/ a0021714

Proulx, C. M. \& Snyder-Rivas, L. A. (2013). The longitudinal associations between marital happiness, problems, and self-rated health. Journal of Family Psychology, 27(2), 194-202. https://doi.org/10.1037/a0031877

Quissini, C. \& Coelho, L. R. M. (2014). A influência das famílias de origem nas relações conjugais. Pensando Famílias, 18(2), 34-47. (DOI INEXISTENTE)

Ramos, M. P. (2002). Apoio social e saúde entre idosos. Sociologias, 4(7), 156-175. https://doi.org/10.1590/s151745222002000100007

Rolim, K. I. \& Wendling, M. I. (2013). A história de nós dois: reflexões acerca da formação e dissolução da conjugalidade. Psicologia Clínica, 25(2), 165-180. https://doi.org/10.1590/s0103-56652013000200010

Rosowsky, E., King, K. D., Coolidge, F. L., Rhoades, C. S., \& Segal, D. L. (2012). Marital satisfaction and personality traits in long-term marriages: an exploratory study. Clinical Gerontologist, 35(2), 77-87. https://doi.org/10.1080/07 317115.2011 .639855

Sabey, A. K., Rauer, A. J., \& Jensen, J. F. (2014). Compassionate love as a mechanism linking sacred qualities of marriage to older couples' marital satisfaction. Journal of Family Psychology, 28(5), 594-603. https://doi. org/10.1037/a0036991

Sandberg, J. G., Miller, R. B., \& Harper, J. M. (2009). The impact of marital conflict on health and health care utilization in older couples. Journal of Health Psychology, 14(1), 9-17. https://doi.org/10.1177/1359105308097938

Santos, C. M. C., Pimenta, C. A. M., \& Nobre, M. R. C. (2007). A estratégia para a construção da pergunta de pesquisa e busca de evidências. Revista Latino-Americana de Enfermagem, 15(3), 508-511. https://doi.org/10.1590/S010411692007000300023

Sardinha, A., Falcone, E. M. O., \& Ferreira, M. C. (2009). As relações entre a satisfação conjugal e as habilidades sociais percebidas no cônjuge. Psicologia: Teoria e Pesquisa, 25(3), 395-402. https://doi.org/10.1590/s010237722009000300013

Silva, L. A., Scorsolini-Comin, F., \& Santos, M. A. (2017). Casamentos de longa duração: recursos pessoais como estratégias de manutenção do laço conjugal. Psico-USF, 22(2), 323-335. https://doi.org/10.1590/141382712017220211

Strey, M. N., Ploner, K. S., Michaels, L. R. F., \& Oliveira, M. A. M. (1999). O significado de envelhecer para homens e mulheres. In A. F. Silveira, C. Gewehr, L. F. R. Bonin, \& Y. L. M. Bulgacov (Orgs.), Cidadania e participaçãa social (pp. 157-172). Porto Alegre: Abrapsosul. https://doi.org/10.7476/9788599662885

Valdanha, E. D., Scorsolini-Comin, F., Peres, R. S., \& Santos, M. A. (2013). Influência familiar na anorexia nervosa: em busca das melhores evidências científicas. Jornal Brasileiro de Psiquiatria, 62(3), 225-233. https://doi.org/10.1590/s0047-20852013000300007

Vieira, E. D. \& Stengel, M. (2010). O "nós" do individualismo e da conjugalidade na pós-modernidade. Aletheia, 32, 147-160. (DOI INEXISTENTE)

Zordan, E. P., Falcke, D., \& Wagner, A. (2009). Casar ou não casar? Motivos e expectativas com relação ao casamento. Psicologia em Revista, 15(2), 56-76. https://doi.org/10.5752/p.1678-9563.2009v15n2p56

\footnotetext{
Dados dos autores: em Pesquisa do CNPq PQ-2.

Bolsista de Produtividade em Pesquisa do CNPq PQ-1A.

\section{Endereço para correspondência:}

Fabio Scorsolini-Comin

Departamento de Enfermagem Psiquiátrica e Ciências Humanas

Escola de Enfermagem de Ribeirão Preto, Universidade de São Paulo

Av. Bandeirantes, 3900 - Monte Alegre

14049-900, Ribeirão Preto, SP, Brasil

E-mail: fabio.scorsolini@usp.br

Recebido em: 16/04/2018

Aceito em: 06/12/2018.

Publicado em: 05/08/2019.
}

Suzel Alves Goulart - Mestre em Psicologia, Universidade Federal do Triângulo Mineiro.

Ana Carolina Graner Araújo Oliveira - Psicóloga, Universidade Federal do Triângulo Mineiro.

Fabio Scorsolini-Comin - Professor Doutor, Escola de Enfermagem de Ribeirão Preto, Universidade de São Paulo. Bolsista de Produtividade

Manoel Antônio dos Santos - Professor Titular, Faculdade de Filosofia, Ciências e Letras de Ribeirão Preto, Universidade de São Paulo. 